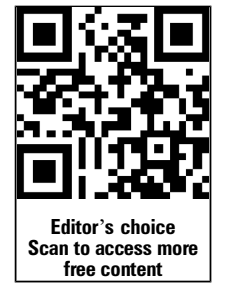

${ }^{1}$ UCT/MRC Research Unit for Exercise Science and Sports Medicine, Department of Human Biology, University of Cape Town, Cape Town, Western Cape, South Africa ${ }^{2}$ Dynamics of Human Motion Laboratory, School of Biomedical Engineering, Dalhousie University, Halifax, Nova Scotia, Canada

Correspondence to Nicholas Tam, UCT/MRC Research Unit for Exercise Science and Sports Medicine, Department of Human Biology, University of Cape Town, PO Box 115, Newlands, Cape Town 7725,

South Africa;

tamright@gmail.com

Accepted 4 September 2013

Published Online First

9 October 2013

\title{
Barefoot running: an evaluation of current hypothesis, future research and clinical applications
}

\author{
Nicholas Tam, ${ }^{1}$ Janie L Astephen Wilson, ${ }^{2}$ Timothy D Noakes, ${ }^{1}$ Ross Tucker ${ }^{1}$
}

\section{ABSTRACT}

Barefoot running has become a popular research topic, driven by the increasing prescription of barefoot running as a means of reducing injury risk. Proponents of barefoot running cite evolutionary theories that longdistance running ability was crucial for human survival, and proof of the benefits of natural running.

Subsequently, runners have been advised to run barefoot as a treatment mode for injuries, strength and conditioning. The body of literature examining the mechanical, structural, clinical and performance implications of barefoot running is still in its infancy. Recent research has found significant differences associated with barefoot running relative to shod running, and these differences have been associated with factors that are thought to contribute to injury and performance. Crucially, long-term prospective studies have yet to be conducted and the link between barefoot running and injury or performance remains tenuous and speculative. The injury prevention potential of barefoot running is further complicated by the complexity of injury aetiology, with no single factor having been identified as causative for the most common running injuries. The aim of the present review was to critically evaluate the theory and evidence for barefoot running, drawing on both collected evidence as well as literature that have been used to argue in favour of barefoot running. We describe the factors driving the prescription of barefoot running, examine which of these factors may have merit, what the collected evidence suggests about the suitability of barefoot running for its purported uses and describe the necessary future research to confirm or refute the barefoot running hypotheses.

\section{INTRODUCTION}

Barefoot running has recently gained significant attention, both in scientific publications as well as in the lay media as a result of its alleged benefits for runners of all levels. These benefits include the potential for reduced injury risk, more economical running and, broadly speaking, a better understanding of running biomechanics. The translation of scientific theories into popular lay publications such as 'born to run' ${ }^{1}$ has transformed barefoot running into a topic of interest not only to scientists and clinicians, but also to all runners.

Recently, Lieberman ${ }^{2}$ supported the theoretical basis for barefoot running, concluding that humans evolved adaptations to optimise barefoot running, and that the biomechanics of such a style would minimise impact peaks, increase proprioception and foot strength and thus help prevent injury regardless of the choice of footwear. There remains a lack of conclusive evidence proving or refuting the proposed advantages of barefoot running, however. Such evidence will require long-term longitudinal studies and further understanding of the biomechanics and implications of barefoot running. To date, the failure to conclusively explain the implications of barefoot running on injury risk and performance appear to be the result of four factors

I. The complexity of injury aetiology-injuries are rarely the result of a single risk factor, and the physiological and biomechanical changes associated with barefoot running can only ever address part of the complex array of causative factors for injury;

II. Large variability in mechanics between individuals, with respect to shod running and in the barefoot condition;

III. Differences in study design and methodology, such as overground and treadmill running, minimalist, shod and barefoot conditions;

IV. The volumes of data acquired from biomechanical and neuromuscular analysis during running gait are often not analysed appropriately and lead to spurious conclusions.

The aim of this review was to evaluate the merits of the theoretical factors driving the current scientific interest in barefoot running. These theoretical factors include anthropological/evolutionary theories, biomechanical factors associated with injury and performance outcomes. Understanding the rationale for barefoot running's purported benefits is important, since it drives future research approaches and methods to confirm or refute those benefits. We aim to evaluate current research evidence on the effectiveness of barefoot running as a means to reduce injury risk and improve performance, and suggest necessary future research to enable definitive and practical conclusions for clinicians, researchers and ultimately, runners.

\section{FACTORS DRIVING THE PROMOTION OF BAREFOOT RUNNING}

Evolutionary/anthropology explanation, and the epidemiology of injury

A recent series of articles has proposed that among the many distinctive characteristics of humans, the ability to run long distances may have been instrumental in the evolution of the present human form, ${ }^{3}$ and has led to the description of barefoot running as the most natural means of running. ${ }^{2}$

An extension of this theory is the mismatch hypothesis, where humans are suggested to be maladapted to wearing shoes in ways that may influence injury development. ${ }^{2}$ Limited foot proprioception, altered running form and weak and inflexible feet are the primary maladaptations proposed to prevent the lower limbs from adapting to external forces 
and loads, controlling for excess movement and adjusting to ground surface types appropriately. ${ }^{45}$

These claims and hypotheses remain unproven in the scientific literature. Lieberman ${ }^{2}$ also emphasises that "how one runs probably is more important than what is on one's feet, but what is on one's feet may affect how one runs" referring back to the unnatural environment that shoes provide the body.

With respect to the evolution of footwear, evidence exists that humans have worn footwear such as sandals or primitive moccasins for the past 50000 years, ${ }^{6}$ and that humans gradually adapted to increased use of footwear. ${ }^{67}$ However, significant changes occurred as a result of the increased participation in running as a form of exercise for health. In the 1970s, the appeal of mass participation in endurance running was popularised as a means to prevent and manage chronic diseases of lifestyle, ${ }^{8}$ and ushered in the era of the modern running shoe.

Data gathered since have shown the prevalence of running-related injuries to range between $50 \%$ and $79 \%$ / annum. ${ }^{4}$ 9-12 The research response to injury has focused on the forces applied to the body and 'abnormal' joint angle changes of the body, with the working hypothesis that excessive forces or extreme movements during the gait cycle expose the body to extreme stresses which significantly increase injury risk. $^{5} 13$

Perhaps the simplest example of this is the reported association between bone stress fractures and higher ground reaction forces. ${ }^{14}$ Subsequently, an emphasis to reduce ground reaction forces and joint motion were introduced through technologies such as an increased heel bevel, softer and thicker sole cushioning and dual-density medial midsole support, ${ }^{13}$ with the expectation that these excessive kinetic and kinematic changes could be reduced below a safe stress limit to allow injury-free running.

However, the initial hypothesis that minimising impact forces and joint angle changes to reduce injury risk has since been revealed as oversimplified. ${ }^{15}$ Indeed, it has even been challenged as fundamentally flawed, ${ }^{13}$ with impact forces either being only part of, or completely unrelated to, the development of injury. Instead, it has been proposed that neuromuscular adjustments, made in response to impact forces, regulate the degree of soft tissue vibration and stress and the degree of cushioning on the foot is largely irrelevant. ${ }^{13}$

Of interest is that the incidence of running-related injuries has remained unchanged despite these modern running shoe interventions, ${ }^{9}{ }^{11-13}$ with critical reviews stating that there is no scientific evidence supporting the prescription of a shoe with an elevated cushioned heel and pronation control system. ${ }^{16}$ The concurrent evolution of modern shoes, the lack of evidence for shoe prescription and the persistently elevated prevalence of running injuries have been proposed as evidence that shoe technologies are ineffective, and with a somewhat large leap in logic, that barefoot running would provide the effective and viable alternative. The apparent failure of modern shoe technology to impact the running injury rate may however be due to numerous confounding factors. Primary among them is that while numerous risk factors relating to training volume and intensity and injury history are known to exist, research has still not identified a single common mechanical variable that predicts a range of running-related injuries. ${ }^{4}$

Another factor that must be borne in mind is that injury statistics must be interpreted in the context of running as a past-time today, compared with running as a sport in the 1970s. For example, the New York Marathon saw 14546 runners participated in 1983, compared with 31791 runners in 1999 and $>47000$ runners in $2011 .{ }^{17}$ Arguably, as participation grew exponentially, the biomechanical, anthropological and training characteristics of runners will have changed over time, with modern runners displaying a far greater heterogeneity, and possibly unfavourable characteristics. Since each characteristic can be implicated in injury aetiology (eg, higher body mass, less training history and generally reduced athleticism), one hypothesis is that in the absence of modern shoe technology, the modern running group would present with even higher injury rates-these individuals may not, to borrow from a popular lay publication from above, be 'born to run', and running shoes may in fact be reducing their injury risk compared with the shoes they would have run in many years before. Simply pointing to injury prevalence statistics and the coincident development of shoes as evidence that modern shoes are ineffective is an inadequate oversimplified argument. ${ }^{16}$

\section{Biomechanical justification}

The biomechanical justification for barefoot running centres on the concept that the differences between barefoot running are favourable and reduce the risk of injury. Therefore, it is constructive to evaluate these differences, and ask whether literature exists to support the notion that the shod-to-barefoot change results in biomechanical differences that are injury preventative. For example, Lieberman $e t a l^{18}$ have recently proposed that the most favourable difference between shod and barefoot running is the significant reduction in impact transient or loading rate in the barefoot condition. This is deemed significant because the magnitude of this impact transient has been correlated with the risk of tibial stress injuries. ${ }^{19}$

This approach is complicated significantly by the aetiology of running injuries and, in some instances, conflicting evidence around the strength of the association between certain factors and injury risk. Therefore, our theoretical approach in evaluating the merits of barefoot running is by no means definitive or conclusive. However, it may provide (1) practical and clinical application of research on barefoot running biomechanics for the management or prediction of injury; and (2) highlight where future research can strengthen theoretical concepts for barefoot running.

\section{Practical and clinical application of barefoot running for the management or prediction of injury}

The table below summarises the barefoot running research and its potential implications for injury risk. For each injury, we have summarised the biomechanical factors known to be associated with common running injuries, including bone stress fractures of the tibia and foot, patellofemoral pain, musculoskeletal injury and Achilles tendinopathy. ${ }^{20-27}$ The biomechanical factors are not necessarily causal, but are known to be present in runners with these injuries. We then summarise the changes associated with barefoot running, and suggest whether this change is beneficial or potentially detrimental. These concepts are discussed in detail subsequently (table 1).

\section{Footstrike}

There has been something of a preoccupation with the footstrike as a marker for clinical risk with barefoot running, presumably since it is relatively easily measured. The fundamental premise is that a forefoot strike, associated with flatter foot placement at touchdown, ${ }^{40}{ }^{41}$ greater plantarflexion and greater knee flexion angle on impact, distribute the impact force across a greater surface area than the heel alone, thus cushioning the impact. Further, it has been proposed that the plantar fascia is used to create a support system for the arch of the foot and acts 
Table 1 Biomechanical and neuromuscular risk factors associated with major running-related injuries and the possible theoretical and clinical implications barefoot (BF) running may have on them

\begin{tabular}{|c|c|c|c|c|}
\hline Variable/injury & $\begin{array}{l}\text { Changes associated with } \\
\text { injury in published } \\
\text { literature }\end{array}$ & $\begin{array}{l}\text { Changes associated with BF } \\
\text { running }{ }^{1828}\end{array}$ & $\begin{array}{l}\text { Theoretical } \\
\text { implication }\end{array}$ & Summary and potential clinical outcomes (if known) \\
\hline \multirow{5}{*}{$\begin{array}{l}\text { Stress fractures of } \\
\text { the tibia } \\
\text { Ref. } 2930\end{array}$} & Increased hip adduction & Unknown & Unknown & \multirow{5}{*}{$\begin{array}{l}\text { Potential to reduce risk of tibial stress fractures, but only } \\
\text { if impact forces are lower, may depend on other factors. } \\
\text { Clinical case series suggests increased risk early during } \\
\text { adaptation }\end{array}$} \\
\hline & Increased rearfoot eversion & Increased rearfoot eversion & Increased risk & \\
\hline & Increased free moment & Unknown & Unknown & \\
\hline & Increased impact peak & $\begin{array}{l}\text { Decreased impact peak in some } \\
\text { runners }\end{array}$ & Reduced risk & \\
\hline & $\begin{array}{l}\text { Increased ground reaction } \\
\text { force }\end{array}$ & $\begin{array}{l}\text { Decreased ground reaction force } \\
\text { in some runners }\end{array}$ & Reduced risk & \\
\hline \multirow{4}{*}{$\begin{array}{l}\text { Stress fractures of } \\
\text { the metatarsals } \\
\text { Ref. } 213132\end{array}$} & \multirow[t]{2}{*}{$\begin{array}{l}\text { Increased peak pressure } \\
\text { under metatarsal head }\end{array}$} & $\begin{array}{l}\text { Increased peak pressure under } \\
\text { metatarsal heads }\end{array}$ & Increased risk & \multirow{4}{*}{$\begin{array}{l}\text { BF running may increase risk of metatarsal stress } \\
\text { fractures as greater application of force for both initial } \\
\text { contact and propulsion is experienced }\end{array}$} \\
\hline & & $\begin{array}{l}\text { Decreased peak pressure heel, } \\
\text { midfoot and hallux }\end{array}$ & Unknown & \\
\hline & $\begin{array}{l}\text { Earlier peak rearfoot } \\
\text { eversion }\end{array}$ & Unknown & Unknown & \\
\hline & Increased forefoot loading & Increased forefoot loading & Increased risk & \\
\hline Patellofemoral pain & Increased impact peak & Decreased impact peak & Decreased risk & \multirow[t]{4}{*}{ BF running may reduce forces experienced by the knee } \\
\hline \multirow[t]{3}{*}{ Ref. ${ }^{2033-35}$} & $\begin{array}{l}\text { Increased eccentric load on } \\
\text { knee }\end{array}$ & $\begin{array}{l}\text { Unknown for BF but conscious } \\
\text { forefoot strike may decrease } \\
\text { eccentric load }\end{array}$ & Decreased risk & \\
\hline & Poor gluteal strength & Unknown & Unknown & \\
\hline & Hamstring inflexibility & Unknown & Unknown & \\
\hline $\begin{array}{l}\text { Achilles } \\
\text { tendinopathy }\end{array}$ & Increased rearfoot eversion & Increased rearfoot eversion & Increased risk & \multirow{6}{*}{$\begin{array}{l}\text { BF running may result in greater eccentric loading on the } \\
\text { ankle. Chronic high velocity eccentric loading during } \\
\text { running may increase the risk of injury. However, } \\
\text { eccentric loading may be beneficial in relieving Achilles } \\
\text { tendinopathy if controlled }{ }^{35}\end{array}$} \\
\hline \multirow[t]{5}{*}{ Ref. ${ }^{36-38}$} & $\begin{array}{l}\text { Increased ankle dorsiflexion } \\
\text { at impact }\end{array}$ & $\begin{array}{l}\text { Increased ankle plantarflexion at } \\
\text { impact }\end{array}$ & Decreased risk & \\
\hline & Decrease leg abduction & Unknown & Unknown & \\
\hline & $\begin{array}{l}\text { Decreased knee range of } \\
\text { motion }\end{array}$ & $\begin{array}{l}\text { Decreased knee flexion at } \\
\text { ground contact }\end{array}$ & Increased risk & \\
\hline & $\begin{array}{l}\text { Decreased tibialis anterior, } \\
\text { gluteus medius and rectus } \\
\text { femoris activity }\end{array}$ & Increased gastrocnemius activity & Unknown & \\
\hline & Early pronation & Unknown & Unknown & \\
\hline Plantar fasciitis & $\begin{array}{l}\text { Increased vertical ground } \\
\text { reaction force }\end{array}$ & $\begin{array}{l}\text { Decreased ground reaction force } \\
\text { in some runners, significantly } \\
\text { increased in others }\end{array}$ & $\begin{array}{l}\text { Risk dependent on } \\
\text { individual response to } \\
\text { BF running }\end{array}$ & \multirow{5}{*}{$\begin{array}{l}\text { BF running may aid in attenuating the associated risk } \\
\text { factors. However, these beneficial changes may be } \\
\text { acquired only after habituation to BF running in some } \\
\text { individuals }\end{array}$} \\
\hline \multirow[t]{4}{*}{ Ref. $^{39}$} & Increased loading rates & $\begin{array}{l}\text { Decrease loading rates in some } \\
\text { runners, increased in others }\end{array}$ & Beneficial & \\
\hline & $\begin{array}{l}\text { Lower medial longitudinal } \\
\text { arch }\end{array}$ & Raised medial longitudinal arch & Decreased risk & \\
\hline & Increased foot pronation & Unknown & - & \\
\hline & $\begin{array}{l}\text { Decreased ankle } \\
\text { dorsiflexion range of } \\
\text { motion at impact }\end{array}$ & $\begin{array}{l}\text { Decreased ankle dorsiflexion } \\
\text { range of motion at impact }\end{array}$ & Increased risk & \\
\hline
\end{tabular}

as a shock absorber and facilitate elastic restitution during running, ${ }^{4142}$ and the shift to a more anterior footstrike changes the distribution of eccentric forces across the joints, with an increase in ankle eccentric work and concomitant decrease in loading on the knee joint. ${ }^{43}$

Complicating the discussion, however, is disagreement in findings relating footstrike to running speed. Hasegawa et $a l^{44}$ and Hayes and Caplan ${ }^{45}$ found that forefoot striking is more prevalent among faster runners, whereas Larson et al found no difference in footstrike among recreational runners with varying performance abilities. Further, discrepancies may have also been a result of both sample population (recreational vs competitive) and size. The strict characterisation of barefoot runners as forefoot strikers and shod runners as heel strikers is an oversimplification, and possibly incorrect. ${ }^{45} 46$ Indeed, a recent study by Hatala et al showed that heel striking was relatively common among a habitually barefoot population, with $72 \%$ landing on their heels at their preferred running speed. Although, as running speed increased, footstrike shifted towards the forefoot, but a significant percentage (40\%) remains heel strikers. Thus, the suggestion that barefoot running is synonymous with forefoot striking is thus inaccurate and may obscure the real kinematic differences and their effects on injury risk. ${ }^{47}$ Interestingly, landing surfaces have been shown to influence the footstrike pattern in runners similarly to the different shoe conditions (and the absence of shoes). Thus, these surface differences may explain discrepancies and unusual findings in different studies and should be noted in future studies involving running. ${ }^{48}$

Nevertheless, numerous studies have associated footstrike with injury risk. Most recently Daoud et $a l^{49}$ found that runners who habitually rearfoot strike incur a higher injury rate of repetitive stress injuries when compared with runners who 
mostly forefoot strike. The authors propose that the absence of the impact peak in the ground reaction force during a forefoot strike compared with a rearfoot strike may contribute to lower rates of injury. If this hypothesis is correct, there may be many implications for the running community. However, it must be noted that this study account for performance ability, and the small sample size of 52 runners were divided into 36 rearfoot strikers and 16 forefoot strikers in each group, suggests that further research is required, with larger populations, equally distributed strike types, the type of runner and over a longer period. Alongside this, to categorise footstrike patterns in three clusters may be somewhat reductionist when foot striking has been shown to exist as a spectrum. ${ }^{50}$

The argument for barefoot running based on this research must however be understood in the light of research from Lieberman et al which found that some habitually shod individuals who run barefoot experience greater impact peaks and rates of loading than habitually barefoot runners. ${ }^{51}$ This is presumably because they do not adjust their footstrike and continue to land on the heel, exposing them to loading rates sevenfold greater than when in shoes. ${ }^{18}$ Thus, barefoot running is not by itself sufficient to produce this purported reduction in injury risk, and the transition, which is the logical clinical implication of the advice given to runners, may increase risk, albeit transiently.

\section{Lower limb and foot}

Evidence from habitually shod runners indicate that barefoot running may increase the risk of stress fractures of the lower limb and foot. ${ }^{26}$ Salzler et al presented a case-series of 10 runners who experienced stress fractures primarily on the second and third metatarsal when transitioning to barefoot running. Also, a case of a calcaneal stress fracture was presented. This latter injury is typically the result of direct loads through the heel, and may further indicate that not all runners instinctively adopt a forefoot striking pattern on initial exposure to barefoot running, as discussed previously. ${ }^{26}$ Those who do adopt a forefoot landing may be susceptible to increased risk of stress fractures of the metatarsals, based on the increased forefoot loading and documented cases of such injuries occurring. ${ }^{35}$

\section{Ankle and foot}

Arendse $e t a l^{43}$ found that when runners consciously adopted the POSE technique (a forefoot landing pattern with the absence of a heel strike) while still wearing shoes, there was a decrease in net moments around the knee but an increased net moment around the ankle. These findings were suggested to have positive implications for knee injury, since previous research has attributed knee injuries to high eccentric workloads on the joint. This theory, extended to the ankle, however, would predict an increased risk of ankle and calf muscle or Achilles tendon injury, and this has indeed been documented as a potential risk factor by Salzler et $a l^{26}$ However, whether the POSE technique is indeed typical of barefoot running remains questionable.

It may also be suggested that barefoot running would be most beneficial to runners suffering or recovering from plantar fasciitis. Previous research has associated this injury with increased forces, loading rates and decreased range of motion, ${ }^{39}$ all factors that barefoot running is known to alter favourably in those individuals who adopt a favourable landing pattern (table 1). Once again, the research of Lieberman ${ }^{18}$ suggests that some runners may actually experienced increased forces and loading rates. At this early stage, this has only been associated with footstrike, but future research will need to investigate why some runners experience significantly higher forces (sevenfold higher, as per Lieberman et al) when running barefoot, particularly initially.

With respect to Achilles tendinopathy, research has linked ground contact sole angle, greater plantar torque and dorsiflexion torque, and earlier and increased foot pronation as causative factors. ${ }^{37}$ Additionally, Azevedo et $a l^{36}$ found lower knee range of motion at contact to midstance and lower calf muscle activity in patients with Achilles tendinopathy, though this may be the result of, rather than the cause of the injury. Given this evidence, in particular the greater plantarflexion torque, it may be that barefoot running, with increased plantarflexion on impact and eccentric work on the ankle, may further increase the risk of Achilles tendinopathies. Alternatively, it may be argued that the ankle joint changes associated with habitual barefoot running may alter factors such as foot pronation, thus reducing the injury risk. This is an illustrative case of how oversimplified the barefoot-injury relationship is.

The ability for the neuromuscular system to coordinate the lower limbs appropriately when barefoot running has yet to be fully explored. Some evidence has shown that the calf muscle group activity is greater in the barefoot condition, ${ }^{41}$ and this may be indicative of increased strain on the calf muscle and resultant increased risk of Achilles tendinopathy or a stimulus for the body to adapt. Alternatively, the increased muscle activity may be beneficial, as it may dampen and control the forces applied to the joints and research has shown that triggering the calf with an eccentric load may be a treatment modus for Achilles tendinopathy. ${ }^{38}$

\section{Knee}

It has been found that a forefoot striking running technique (POSE technique) is associated with reduced eccentric loading of the knee and preparatory knee flexion prior to landing. ${ }^{43}$ This is suggested to be of potential benefit to athletes with patellofemoral pain, since previous research had linked eccentric work on the knee to this injury. ${ }^{34}$ However, patellofemoral pain has also been associated with weak gluteal strength and hamstring flexibility, ${ }^{20} 3334$ and so the interaction of these factors, with barefoot running make any suggestion regarding its benefits tenuous.

Another factor, not only limited to the knee, but also the ankle and hip, is that many researchers have reported a reduction stride length and an increase in step frequency during barefoot running. These are biomechanical 'outcome' variables of joint mechanics, but may also affect the loading rate and magnitude of loading on all joints. To date, most studies have correlated these changes to performance rather than injury, ${ }^{51-53}$ but it must be acknowledged that this change, while not specific to a joint, may be an important factor in understanding injury in terms of a loading rate model or explanation.

In conclusion, the complexity of running injuries, which have a multifactorial aetiology, and the highly variable response of many kinetic and kinematic factors associated with barefoot running, make definitive statements about potential benefits impossible. Only with longitudinal intervention studies will evidence emerge regarding the risk of injury when running barefoot, while mechanisms may require significantly more research to elucidate.

\section{FUTURE RESEARCH THAT MAY IMPROVE PRACTICAL BAREFOOT RUNNING RECOMMENDATIONS Skill acquisition of barefoot running}

An as yet unexplored area of barefoot running theory is the process by which biomechanical adaptations occur and whether these are universally learnt. This is crucial both clinically and 
practically, because some individuals may be incapable of achieving the potentially favourable biomechanical changes. These individuals may be exposed to increased risk of injury according to the previously described factors, particularly early on, and fully understanding the process by which the barefoot condition changes biomechanics is crucial to the clinical and performance management of an athlete.

Research has demonstrated immediate adjustments in factors such as ankle and knee angle on impact, and resultant changes in footstrike, but that these changes do not occur equally for all runners. Lieberman et $a l^{18}$ found that when habitually shod runners ran barefoot, $83 \%$ continued to heel strike, at least during the laboratory testing period. In this condition (barefoot and heel striking), the impact force was $8.6 \%$ greater than shod, while the rate of loading was approximately $700 \%$ greater. Thus, the acute response of a majority of runners to barefoot running exposes them to impact forces and loading rates that are significantly higher than when shod. As we described previously, these runners may face substantially more risk when barefoot, and confirms previous research which found that habitually shod runners exhibit higher loading rates when barefoot than in the shod condition. ${ }^{184154}$

Several important questions are raised as a result of these findings. First, the widely popularised theory that shod runners heel strike while barefoot runners shift to a forefoot landing is a generalisation and oversimplification, since $50 \%$ of runners participating in a 6-week minimalist running shoe intervention remained heel strikers. ${ }^{18}$ A more recent study found that even in habitually barefoot individuals, $72 \%$ were heel strikers at comfortable running speeds, and the simple allocation of barefoot runners to the forefoot striking group is clearly false. ${ }^{47}$ Studies do show a significant change in ankle angle on impact, but this is often not sufficient to change footstrike pattern, and as mentioned, may expose those runners to increased impact forces and loading rates.

Second, the findings of Lieberman et al compel the question of whether biomechanical changes in the barefoot condition are learned responses, and thus whether all runners can achieve these adjustments equally. Since habitually barefoot runners present with markedly different kinematic and kinetic characteristics than novice barefoot runners, it is reasonable to propose that a substantial learning component exists. Lieberman et al found, for example, that 6 weeks of training with minimalist shoes designed to simulate barefoot running resulted in changes in the simple outcome variable of footstike pattern. Approximately half of the initial heel strikers had shifted to a forefoot landing pattern after 6 weeks of minimalist shoe training, despite no conscious instruction or feedback. ${ }^{18}$

What is intriguing is whether the other half, who were heel strikers on first exposure to barefoot running and after 6 weeks of training, would remain as such or whether they too would slowly achieve the biomechanical changes that would ultimately characterise them as forefoot strikers. More importantly, would these individuals all achieve the supposedly favourable reductions in impact force and loading rate, or are some runners incapable of these adjustments? These researchers did not present kinetic data on these individuals, and measured footstrike patterns only at 0 and 6 weeks, thus the temporal changes of other biomechanical variables are not known.

Given this question, it seems premature to advocate that barefoot running or the associated biomechanics of barefoot running are desirable, because certain individuals may be incapable of achieving the adjustments and thus may be at increased risk of injury. It may be that individuals who fail to adjust their running biomechanics favourably do not persist with barefoot running. In contrast, runners who succeed barefoot, without injury or discomfort, may be those runners who are able to quickly make favourable changes to their running mechanics. Thus, the ability to run barefoot with proposed favourable reductions in impact force and loading rate may determine the longer term clinical outcome. However, the changes in biomechanical variables occurring over time have not been studied.

It would seem likely that habitually shod runners transitioning to barefoot running would achieve progressive changes in kinematics such as increased plantarflexion and knee flexion angle, and resultant reductions in impact force and loading rate. Accordingly, barefoot running may not be immediately effective, but rather is learned as a skill, with favourable running mechanics the result of achieving a certain skill level.

This skill acquisition must reflect altered neuromuscular activation patterns at various stages during the gait cycle, including altered activation of the calf muscle group to facilitate plantarflexion prior to impact, as well as of the quadriceps to allow for observed differences in knee flexion during the impact phase. ${ }^{41}$ Supporting this, Divert et al found that the muscle activity in the calves when running barefoot was significantly higher than when shod. It was proposed that the noticeably higher preactivation of the lower limb muscles when performing sufficient steps may lead to a reduction in impact peak and subsequent reduction of the mechanical stress during running. ${ }^{41}$ The rate at which the muscle-tendon structures and neuromuscular control of the lower limb can be learned over time may determine successful transition to barefoot running.

Research is required to differentiate between these theories, and more importantly, to discover whether this 'skill' can be learned equally by all runners. This is important for the practical application and proponents of barefoot running, because the initial exposure to barefoot running may increase the risk of injury by virtue of the higher impact forces and loading rates. ${ }^{5}$ Thus, prescribing barefoot running as a clinical treatment modus is premature, however, it appears changing ones footstrike when injured or recovering from injury may assist in alleviating or preventing further specific classes of injury. ${ }^{55}$

\section{Fatigue (as an indicator of adaptation)}

An under-researched but likely crucial factor for barefoot running is the effect of fatigue on running mechanics, muscle function and joint integrity. Running consists of repetitive muscle contractions which unavoidably subjects the body to various levels of muscular fatigue (inability to maintain a given level of force production). ${ }^{5657}$ It has been proposed that muscle is essential for dissipating large dynamic loads experienced in the lower extremity during movement. ${ }^{58}$ This is primarily achieved through the stretch-shortening cycle and possible muscle tuning. Interestingly, $\mathrm{Nigg}^{13}$ has proposed that muscle tuning may have the capacity to dampen impact peaks during running. This hypothesis may have bearing on fatigue (adaptation) as the inability for the muscle tune appropriately may result in reduced dampening of impact forces, with a resultant increase in force transmission elsewhere. ${ }^{59}$ However, as fatigue develops over the duration of exercise, the protective neuromuscular mechanism of the muscle diminishes. ${ }^{58}$

Exercising in a fatigued state increases stress, strain and impact forces, particularly on the lower extremity. ${ }^{60}$ Although these loads in isolation may not be above the physiological threshold for injury, it has been hypothesised that they accumulate and lead to various overuse injuries. ${ }^{10} 61$ For example, Mizrahi et $a l^{1462}$ have shown that fatigue influences the lower 
extremity limb mechanics during running, with altered contraction of the muscle on the shank (an increase in gastrocnemius and decrease in tibialis anterior activity), imbalances in the transfer of mechanical energy between eccentric and concentric muscle contractions and slower muscle reaction time.

Further, after localised muscle fatigue has been induced, there are significant altered patterns of ground reaction forces and reduced ankle joint dorsiflexion during running. ${ }^{57}$ It was concluded that localised muscle fatigue may influence many common lower extremity running injuries.

All of these factors affect the resilience of the neuromuscular system to consistently dampen these large forces. Thus, as fatigue develops, the ability to maintain the desired angular displacements during the stance phase may be compromised and subsequent injury may occur. ${ }^{63} 64$ Larson et $a l^{46}$ described footstrike patterns of runners at the 10 and $32 \mathrm{~km}$ mark of a marathon, and found a 5.2\% increase in rearfoot striking as the race progressed. These changes provide broad insight on the influence of fatigue on the ability of the body to execute the most preferred gait.

Given the previously described changes in neuromuscular activation, as well as the changes in joint loading that occur with barefoot running, it seems reasonable to assume that fatigue is a crucial factor that may significantly compromise the body's ability to adapt to the mechanical and muscular changes occurring during barefoot running. ${ }^{65}$ Barefoot running introduces potentially unfamiliar stress on muscle and joints and fatigue may exacerbate the potential risk associated with these stresses. ${ }^{42}$ Fully understanding the risks and benefits of barefoot running, particularly during the early phases of adaptation, requires that the potential effects of fatigue are acknowledged. To date research has been mostly limited to laboratory studies of non-fatigued runners, which reduce the external validity of these findings, since fatigue is a crucial, almost ubiquitous component of running.

\section{Performance (indicated by metabolic and whole-body physiological changes)}

Currently the most researched performance-related variable for barefoot running is its effect on running economy. Studies have found that barefoot running is associated with an improved running economy, though this is widely accepted to be the result of a decrease in mass (absent shoes). Alternatively, it is suggested to be due to the effect of elastic compliance from the foot and the influence of shoe construction on gait. ${ }^{66} 67$

Owing to the mass effect, it is important that studies control for the absence of shoes on economy. Failing this, findings such as that of Hanson et $a l,{ }^{66}$ who found improved running economy in the barefoot compared to the shod condition, are not surprising. Divert et al questioned this difference as the result of shoe construction (wearing shoes alters the gait) or the additional mass of the shoe. When mass was corrected using thin diving socks, they continued to find that running economy was improved when barefoot. It was concluded that the metabolic component was a result of the mass and the net efficiency was due to mechanical alterations in the lower limbs. ${ }^{67}$

In contrast, Perl et $a l^{68}$ recently found that runners were more economical in minimalist shoes than in traditional cushioned shoes when controlling for shoe mass, stride frequency and strike patterns. They did not assess a barefoot condition; however, Franz et al disputed this finding, finding that being barefoot was no more economical than running in lightweight cushioned shoes. No study has compared the minimalist shoe of Perl et al to pure barefoot, lightweight and traditional cushioned shoes, making direct comparison impossible. Currently, the theory is that the difference may be due to the greater elastic energy storage and release as a result of stiffer minimalist shoes, and that no metabolic advantage exists for running barefoot as compared to employing lightweight cushioned shoes when controlling for footstrike pattern and mass. ${ }^{69}$

Although adding mass to the foot predictably worsens running economy, a lightweight $(<150 \mathrm{~g})$ but cushioned shoe maybe more economical than barefoot running. This implies that shoe cushioning may influence running economy to a point where shoe mass would prevail over the cushioning effect.

Interestingly, no studies have shown whether running economy is affected as a result of training in the barefoot condition regardless of whether running in shod or barefoot. Franz et $a l^{69}$ hypothesised that the barefoot running economy would improve with practice/training. Hence investigating the change in running economy in response to barefoot training would provide a novel explanation of possible physiological conditioning of the muscles and increased efficiency in the elastic storage capacity of the lower limbs during running.

\section{Clinical studies of injury rehabilitation through barefoot running}

Finally, given the potential link between mechanics and risk factors for injury, and the documented changes occurring for various joints during barefoot running (table 1), it is intriguing to consider whether barefoot running may be prescribed as a treatment modality for certain individuals. For instance, Diebal et al, 2012 found that using a forefoot strike intervention resolved symptoms of anterior compartment syndrome in 10 patients (Diebal, Gregory, Alitz, and Gerber, 2012). This study suggests that biomechanical changes, achieved consciously in the form of instruction, can be used to treat common running injuries. Barefoot running, which may induce similar changes without the need for instruction and potentially supervision, offers the same potential, though it is an area that warrants further research, and which may be prefaced by the recognition or better understanding of barefoot running as a skill, as described previously.

\section{CONCLUSION}

We have described the rationale, the biomechanical justification and two of the crucial unknown aspects of barefoot running. It is clear that little is known about barefoot running and injury and performance. The current promotion of barefoot running is based on oversimplified, poorly understood, equivocal and in some cases, absent research, but remains a trend in popular media based solely on an evolutionary/epidemiological hypothesis and anecdotal evidence. Here, we have described that while the evolutionary hypothesis may be credible, it assumes a great deal and cannot by itself be the justification for barefoot running. In terms of biomechanics, it is clear from current evidence that barefoot running influences the body acutely, and likely has a significant impact on kinetic and kinematic factors associated with injury. However, no causal relationships, and the high variability and complexity of both injury and barefoot running make this justification tenuous.

Finally, we suggest that barefoot running may be a skill that is not instinctively acquired, but that requires substantial practice in order for the body to adapt. Even then, it is unclear how this adaptation may occur, and whether every runner can achieve it. The process of adaptation needs to be clearly understood before training and clinical advice is disseminated to athletes. 
In conclusion, there remain more questions than answers at present. Future research may elucidate some of these answers, but current advice, based on tenuous justifications and associations between biomechanical factors and injury do not by themselves constitute a compelling argument for barefoot running. It may be that the running technique is more important, and so further research must distinguish between barefoot running and characteristics of barefoot running that may be implementable for shod running.

\section{What this review adds}

- Novel approach to the barefoot running debate evaluating the evidence supporting barefoot running.

- Beneficial changes associated with barefoot running may need to be an acquired skill.

- The link between certain lower limb running injuries and barefoot running are scrutinised.

\section{How might it impact on clinical practice in the near} future

- The prescription of barefoot running for injury prevention and performance may not be purported as a general modus as some researchers hypothesis.

- At this period of time the injury prevalence of barefoot running compared with shod running is unknown.

Contributors NT and TDN were involved in the concept and design of the review and prepared the manuscript. JLAW and RT were involved in the concept and design of the review and the preparation and review of the manuscript.

Funding Discovery Health, the Medical Research Council of South Africa, Deutsche Akademischer Austache Dienst and the National Research Foundation (South Africa) through the Technology and Human Resources for Industry Programme initiative.

Competing interests None.

Provenance and peer review Not commissioned; externally peer reviewed.

\section{REFERENCES}

$1 \mathrm{McDougall}$ C. Born to run: the hidden tribe, the ultra-runners and the greatest race the world has never seen. 1st edn. New York: Random House Inc, 2009:287.

2 Lieberman DE. What we can learn about running from barefoot running. Exerc Sport Sci Rev 2012;40:63-72.

3 Bramble DM, Lieberman DE. Endurance running and the evolution of Homo. Nature 2004;432:345-52.

4 Fields KB, Sykes JC, Walker KM, et al. Prevention of running injuries. Curr Sports Med Rep 2010;9:176-82.

5 Oakley T, Pratt DJ. Skeletal transients during heel and toe strike running and the effectiveness of some materials in their attenuation. Clin Biomech 1988;3:159-65.

6 Trinkaus $\mathrm{E}$, Shang $\mathrm{H}$. Anatomical evidence for the antiquity of human footwear: Tianyuan and Sunghir. J Archaeol Sci 2008;35:1928-33.

7 Rao UB, Joseph B. The influence of footwear on the prevalence of flat foot. A survey of 2300 children. J Bone Joint Surg Br 1992;74:525-7.

8 Noakes TD, Opie LH. The cardiovascular risks and benefits of exercise. Practitioner 1976:216:288-96.

9 Buist I, Bredeweg SW, Lemmink KPM, et al. Predictors of running-related injuries in novice runners enrolled in a systematic training program: a prospective cohort study. Am J Sports Med 2010;38:273-80.

10 Taunton JE, et al. A retrospective case-control analysis of 2002 running injuries. Br J Sports Med 2002;36:95-101.

11 Van Gent RN, Siem D, Van Middelkoop M, et al. Incidence and determinants of lower extremity running injuries in long distance runners: a systematic review. Br J Sports Med 2007:41:469-80.

12 Van Mechelen W. Running injuries. Sports Med 1992;14:320-35.
13 Nigg BM. The role of impact forces and foot pronation: a new paradigm. Clin J Sport Med 2001;11:2-9.

14 Mizrahi J, Verbitsky O, Isakov E. Shock accelerations and attenuation in downhill and level running. Clin Biomech 2000;15:15-20.

15 Nigg BM, Wakeling JM. Impact forces and muscle tuning: a new paradigm. Exerc Sport Sci Rev 2001;29:37-41.

16 Richards CE, Magin PJ, Callister R. Is your prescription of distance running shoes evidence-based? Br J Sports Med 2009:43:159-62.

17 Jokl P. Master's performance in the New York City Marathon 1983-1999. Br J Sports Med 2004;38:408-12.

18 Lieberman DE, Venkadesan M, Werbel WA, et al. Foot strike patterns and collision forces in habitually barefoot versus shod runners. Nature 2010;463:531-5.

19 Zadpoor AA, Nikooyan AA. The relationship between lower-extremity stress fractures and the ground reaction force: a systematic review. Clin Biomech 2011;26:23-8.

20 Dierks TA, Manal KT, Hamill J, et al. Proximal and distal influences on hip and knee kinematics in runners with patellofemoral pain during a prolonged run. $J$ Orthop Sports Phys Ther 2008;38:448-56.

21 Dixon SJ, Creaby MW, Allsopp AJ. Comparison of static and dynamic biomechanical measures in military recruits with and without a history of third metatarsal stress fracture. Clin Biomech 2006;21:412-19.

22 Goss DL, Gross MT. Relationships among self-reported shoe type, footstrike pattern, and injury incidence. US Army Med Dep J 2012;0ct-Dec:25-30.

23 Lee MJ, Reid SL, Elliott BC, et al. Running biomechanics and lower limb strength associated with prior hamstring injury. Med Sci Sports Exerc 2009;41:1942-51.

24 Messier SP, Legault C, Schoenlank CR, et al. Risk factors and mechanisms of knee injury in runners. Med Sci Sports Exerc 2008;40:1873-9.

25 Milner CE, Davis IS, Hamill J. Free moment as a predictor of tibial stress fracture in distance runners. J Biomech 2006;39:2819-25.

26 Salzler MJ, Bluman EM, Noonan $\mathrm{S}$, et al. Injuries observed in minimalist runners. Foot Ankle Int 2012;33:262-6.

27 Lopes AD, Hespanhol LC, Yeung SS, et al. What are the main running-related musculoskeletal injuries? A systematic review. Sports Med 2012;42:891-905.

28 D'AoÛt K, Pataky TC, De Clercq D, et al. The effects of habitual footwear use: foot shape and function in native barefoot walkers. Footwear Sci 2009;1:81-94.

29 Creaby MW, Dixon SJ. External frontal plane loads may be associated with tibial stress fracture. Med Sci Sports Exerc 2008:40:1669-74.

30 Pohl MB, Mullineaux DR, Milner CE, et al. Biomechanical predictors of retrospective tibial stress fractures in runners. J Biomech 2008:41:1160-5.

31 Weist R. The influence of muscle fatigue on electromyogram and plantar pressure patterns as an explanation for the incidence of metatarsal stress fractures. $\mathrm{Am} \mathrm{J}$ Sports Med 2004;32:1893-8.

32 Nagel A, Fernholz F, Kibele C, et al. Long distance running increases plantar pressures beneath the metatarsal heads: a barefoot walking investigation of 200 marathon runners. Gait Posture 2008;27:152-5.

33 Nakagawa TH, Moriya ETU, Maciel CD, et al. Frontal plane biomechanics in males and females with and without patellofemoral pain. Med Sci Sports Exerc 2012:44:1747-55.

34 Thijs Y, De Clercq D, Roosen P, et al. Gait-related intrinsic risk factors for patellofemoral pain in novice recreational runners. Br J Sports Med 2008;42:466-71.

35 Bonacci J, Vicenzino B, Spratford W, et al. Take your shoes off to reduce patellofemoral joint stress during running. Br J Sports Med Published Online First: 13 July 2013 doi:10.1136/bjsports-2013-092160

36 Azevedo LB, Lambert MI, Vaughan $\mathrm{CL}$, et al. Biomechanical variables associated with Achilles tendinopathy in runners. Br J Sports Med 2009;43:288-92.

37 McCrory JL, Martin DF, Lowery RB, et al. Etiologic factors associated with Achilles tendinitis in runners. Med Sci Sports Exerc 1999:31:1374-81.

38 Jonsson $\mathrm{P}$, Alfredson $\mathrm{H}$, Sunding $\mathrm{K}$, et al. New regimen for eccentric calf-muscle training in patients with chronic insertional Achilles tendinopathy: results of a pilot study. Br J Sports Med 2008;42:746-9.

39 Pohl MB, Hamill J, Davis IS. Biomechanical and anatomic factors associated with a history of plantar fasciitis in female runners. Clin J Sport Med 2009;19:372-6.

40 Divert $\mathrm{C}$, Baur $\mathrm{H}$, Mornieux $\mathrm{G}$, et al. Stiffness adaptations in shod running. J Appl Biomech 2005:21:311-21.

41 Divert C, Mornieux G, Baur $\mathrm{H}$, et al. Mechanical comparison of barefoot and shod running. Int J Sports Med 2005:26:593-8.

42 De Wit B, De Clercq D, Aerts P. Biomechanical analysis of the stance phase during barefoot and shod running. J Biomech 2000;33:269-78.

43 Arendse RE, Noakes TD, Azevedo LB, et al. Reduced eccentric loading of the knee with the pose running method. Med Sci Sports Exerc 2004;36:272-7.

44 Hasegawa H, Yamauchi T, Kraemer WJ, et al. Footstrike patterns of runners at the $15-\mathrm{km}$ point during an elite-level half marathon. J Strength Cond Res 2007;21:888-93.

45 Hayes $\mathrm{P}$, Caplan N. Foot strike patterns and ground contact times during highcalibre middle-distance races. J Sports Sci 2012;30:1275-83.

46 Larson P, Higgins E, Kaminski J, et al. Foot strike patterns of recreational and sub-elite runners in a long-distance road race. J Sports Sci 2011;29:1665-73.

47 Hatala KG, Dingwall HL, Wunderlich RE, et al. Variation in foot strike patterns during running among habitually barefoot populations. PLOS ONE 2013;8:e52548. 
48 Gruber AH, Silvernail JF, Brueggemann P, et al. Footfall patterns during barefoot running on harder and softer surfaces. Footwear Sci 2013;5:37-41.

49 Daoud Al, Geissler GJ, Wang F, et al. Foot strike and injury rates in endurance runners: a retrospective study. Med Sci Sports Exerc 2012;44:1325-34.

50 Altman AR, Davis IS. A kinematic method for footstrike pattern detection in barefoot and shod runners. Gait Posture 2012;35:298-300.

51 Squadrone R, Gallozi C. Biomechanical and physiological comparison of barefoot and two shod condition in experienced barefoot runners. J Sports Med Phys Fitness 2009;49:6-13.

52 Heiderscheit BC, Chumanov ES, Michalski MP, et al. Effects of step rate manipulation on joint mechanics during running. Med Sci Sports Exerc 2011;43:296-302.

53 Bonacci J, Saunders PU, Hicks A, et al. Running in a minimalist and lightweight shoe is not the same as running barefoot: a biomechanical study. Br J Sports Med 2013;47:387-92.

54 Robbins SE, Hanna AM. Running-related injury prevention through barefoot adaptations. Med Sci Sports Exerc 1987;19:148-56.

55 Diebal AR, Gregory R, Alitz C, et al. Forefoot running improves pain and disability associated with chronic exertional compartment syndrome. Am J Sports Med 2012;40:1060-7.

56 Millet GY, Lepers R. Alterations of neuromuscular function after prolonged running, cycling and skiing exercises. Sports Med 2004;34:105-16.

57 Christina KA, White SC, Gilchrist LA. Effect of localized muscle fatigue on vertical ground reaction forces and ankle joint motion during running. Hum Mov Sci 2001;20:257-76.
58 Radin EL. Role of muscles in protecting athletes from injury. Acta Med Scand Suppl 1986;711:143-7.

59 Friesenbichler $B$, Stirling $L M$, Federolf $P$, et al. Tissue vibration in prolonged running J Biomech 2011;44:116-20.

60 Dierks TA, Davis IS, Hamill J. The effects of running in an exerted state on lower extremity kinematics and joint timing. J Biomech 2010;43:2993-8.

61 Hohmann E. MR imaging of the hip and knee before and after marathon running. Am J Sports Med 2004;32:55-9.

62 Mizrahi J, Verbitsky O, Isakov E, et al. Fatigue-related loading imbalance on the shank in running: a possible factor in stress fractures. Ann Biomed Eng 2000;28:463-9.

63 Murdock GH, Hubley-Kozey CL. Effect of a high intensity quadriceps fatigue protocol on knee joint mechanics and muscle activation during gait in young adults. Eur J Appl Physiol 2012;112:439-49.

64 Komi PV. Stretch-shortening cycle: a powerful model to study normal and fatigued muscle. J Biomech 2000;33:1197-206.

65 Dierks TA, Manal KT, Hamill J, et al. Lower extremity kinematics in runners with patellofemoral pain during a prolonged run. Med Sci Sports Exerc 2010;43:693-700.

66 Hanson NJ, Berg K, Deka P, et al. Oxygen cost of running barefoot vs. running shod. Int J Sports Med 2011;32:401-6.

67 Divert $C$, Mornieux G, Freychat $P$, et al. Barefoot-shod running differences: shoe or mass effect? Int J Sports Med 2008;29:512-18.

68 Perl DP, Daoud Al, Lieberman DE. Effects of footwear and strike type on running economy. Med Sci Sports Exerc 2012;44:1335-43.

69 Franz JR, Wierzbinski CM, Kram R. Metabolic cost of running barefoot versus shod: is lighter better? Med Sci Sports Exerc 2012;44:1519-25. 